\title{
Machine Translation: The Case of Arabic- English Translation of News Texts
}

\author{
Noureldin Mohamed Abdelaal \\ University of Nizwa, Oman \\ Abdulkhaliq Alazzawie \\ University of Nizwa, Oman
}

\begin{abstract}
This study aims at identifying the common types of errors in Google Translate (GT) in the translation of informative news texts from Arabic to English, to measure the translation errors quality and to assess the fluency and the semantic adequacy of the translation output, and therefore to explain the extent a human translator is needed to rectify the output translation. For this purpose, some examples were purposively selected from online newspapers. The collected data was analyzed using a mixed method approach, as the errors were qualitatively identified, guided by Hsu's (2014) classification of machine translation errors. Quantitative descriptive approach was used to measure the translation errors quality, using the Multidimensional Quality Metrics and Localization Quality Evaluation. As for assessing the semantic adequacy and fluency, a questionnaire that was adapted from Dorr, Snover, and Madnani (2011) was used. The results of the analysis show that omission, which is a lexical error and inappropriate lexical choice, which is a semantic error are the most common errors. Inappropriate lexical choice is sometimes a result of the homophonic nature of some source text words which can be misinterpreted by the machine translation system. This study concludes that it is useful to use machine translation systems to expedite the translation process, but that accuracy is sacrificed for the sake of ease (less work for the human) and speed of translation. If greater accuracy is required, or desired, a human translator must at least proofread and work on the material.
\end{abstract}

Index Terms - Google Translate, translation errors, News, informative texts, semantic adequacy, fluency, translation quality

\section{INTRODUCTION}

Machine translation (MT) is one of the promising technologies in the realm of translation. Translators can no longer translate all the required huge number of texts. MT systems can facilitate and expedite the process of translation. In other words, a translator can use such translation systems, which are sometimes available for free, to translate some types of texts and then the job of a translator would be to post-edit the submitted work to ensure its accuracy. This might help so far as reducing the cost and time of translation is concerned (Aiken \& Balan, 2001). A web-based MT can be accessed freely to expedite the translation process. Some scholars and researchers (e.g., Drugan 2013; Koponen \& Salmi 2015) argue that MT is only useful to get the gist of the meaning of a submitted text. MT cannot be used for a professional translation unless the text is post-edited. However, we argue that these MT systems are not very efficient with every type of text. Maybe, informative texts can be translated using those MT systems. However, some other types of texts, such as expressive texts, may not be suitable for MT because the resulting translation output could be highly flawed.

In this regard, Arnold, Balkan, Humphreys, Meijer and Sadler (1996) argue that MT errors can be categorized under two major types: Problems of ambiguity, and problems that happen due to structural and lexical differences between languages and multiword units (e.g., idioms and collocations). Lexical ambiguity happens when one word has more than one sense and therefore, it is difficult for the machine translator to decide which one is the correct choice in a specific parameter or context. On the other hand, structural ambiguity occurs when one phrase or sentence has more than one possible structure. These problems, however, no longer cause big challenges to GT, as it is currently based on the neural system, which removes or reduces many of these challenges. Ambiguity sometimes results from the fact that one word can be used as a noun and verb in different contexts. Consider the examples below, as provided by Arnold at al. (1996):

1a. The main function of the merchant banks is to raise capital for industry.

1b. On weekdays, one third of the room functions as workspace.

1c. Investment is a function of the interest rate.

As we see in the above examples, the word 'function' can be used as a noun as in (1a) and (1c) or as a verb as in (1b). Although this might seem problematic, thanks to technology this problem can be solved by providing the MT systems with all the required information. Arnold et al., (1996) suggest that an automatic parser can solve the problem by finding out whether the noun or verb form of a particular verb fits in a specific context; this can be achieved by having the parser look at the grammaticality of the source text (ST) word. Looking back at the example provided earlier, we 
can figure out that English does not have an article + verb pattern or the article + adjective + verb pattern. However, we have the pattern of article + noun or article+ adjective+ noun. Therefore, a parser will likely translate the (1a) and (1c) examples as nouns. The problems mentioned by Arnold et al., however, are reduced thanks to the neural system adopted by GT in the last few years.

Therefore, much attention needs to be paid to MT and the common errors of MT systems. This will help provide solutions to the errors produced. This task can be implemented in cooperation between translators, translation theorists and computer engineers. Vilar, Xu, D'Haro, and Ney (2006) claimed that errors in MT can be stratified into five categories: inflectional errors, word order errors, missing words, extra words and incorrect lexical choice. Inflectional errors are the types of errors that ensue due to generating incomplete forms of some ST words. Word order errors are errors that occur due to improper order of the TT words in relation to the ST order. Missing words error happens when some words are missing in the translation output. Extra words are words that do not exist in the ST but were generated by the machine translator in the TT. As for lexical choice errors, they happen when the TT word is not the right equivalent for the ST word. In a more detailed categorization of errors, though earlier, Dagneaux, Denness, and Granger (1996) mentioned that errors in MT can include errors such as subject omission, verb tense, continuous aspect errors, sequence of tenses, conditional clauses, word order, uncountable nouns, prepositions, double negation, indefinite articles, word omissions and lexical confusion.

Condone et al. (2010) examined the errors in MT of submitted English- Iraqi Arabic dialogues. They found that errors included deletions, and insertions. The results showed a high frequency of pronoun errors in the translation to English as well as high frequency of errors in subject person inflection in translation to Iraqi Arabic. They also found errors in word order and plurality. In a similar context, evaluation of machine translation output was conducted by Popovic and Ney (2011). They found some errors, which they categorized into five types, viz., inflectional errors, reordering errors, lexical errors, word deletions, and word insertions.

In spite of the research conducted on MT output to identify the types of errors in the MT output, more studies are needed to investigate errors found in MT output of the different subgenres of informative texts such as news. This research, therefore, aims at identifying some common errors in GT from Arabic to English and to assess the semantic adequacy and fluency of the GT output. This will help guide readers to the extent that a human translator is needed to rectify the translation. This research specifically addresses the following research questions:

1. What are the common types of errors produced by GT in the process of translating Arabic news texts into English?

2. To what extent is the output of GT fluent?

3. To what extent is the output of GT semantically adequate?

\section{LITERATURE REVIEW}

\section{A. History of Machine Translation (MT)}

Ping (2009) postulates that MT is a discipline of translation that employs computer software to translate submitted texts. This system of translation was developed in the 1950's (Hutchins, 1995; Balkan, 1998). It was used at the beginning to produce a raw output for the purpose of providing a preliminary understanding of the submitted source text (ST), which is based on a statistical analysis of the ST. The purpose of MT systems was to replace humans, but it proved to be unsuccessful. Later on, MT developers lost their enthusiasm about using MT systems since the translation output contained lots of errors resulting from lexical and syntactic ambiguity (Juan, 1994). The failure of MT led to the development of computer-assisted translation (CAT), which does not neglect the role of a human translator who rectifies and corrects the translation produced by such computer-based software.

MT systems can be classified into three different types: neural MT (NMT), rule-based MT (RBMT), and statistical machine translation system (SMT). Since 2016, GT (GT) moved from the SMT to the NMT system. NMT system uses artificial neural network to predict the probability of an array of words, typically modeling entire sentences in a single integrated model. This system does not require large space ion memory. NMT models use deep learning and representation learning.

\section{B. Google Translate as a Machine Translation System}

One of the free MT systems is GT which can be accessed freely. One advantage of GT is that it has access to many translation databases or, in other words, too many translations created basically by humans. In this regard, many researchers (e.g., Aziz, Sousa, \& Specia, 2012; Jia et al., 2012; Karami, 2014; Komeili, Farughi, \& Rahimi, 2011) argue that GT is the most popular MT system since it is viewed by 200 million people.

However, as mentioned earlier, GT currently uses the Neural Machine Translation system (NMT). According to Castilho, Gaspari, Moorkens and Way (2017), NMT systems have proved to produce much better translation output in many language pairs if compared to SMT systems. The advantage of NMT lies in the fact that it uses artificial intelligence to represent all the sentences in the target language at once, instead of breaking them into small chunks such as phrases or words.

In relation to this, Handschuh (2013), in a study conducted on German-English translation using four different online MT systems, viz. GT, SYSTRAN, Bing and Babylon, found that MT's output is mostly erroneous and inaccurate. Keshavarz (1999) argued that the errors fall under lexico-semantic errors such as the wrong use of tenses, errors in the 
use of verb groups, errors in word order, incorrect use of prepositions, incorrect use of the active and passive voice as well as errors related to the use of articles. Some researchers (e.g., DeCamp, 2009; Vilar, Xu, D’Haro \& Ney, 2006) found that the most frequent error in MT output is omission. Some other researchers (e.g., Gaspari, Toral \& Naskar, 2011; Valotkaite \& Asadullah, 2012) found that mistranslations are the most frequent errors in MT.

Lotz and Rensburg (2016) conducted a study on two types of texts, namely, texts from a slide-show presentation and texts from an online news report. Over a period of four years (from 2010 to 2013), the same two texts were submitted to GT to check the extent to which the quality of MT output was improved. Omission, mistranslation, non-translation and grammar were the most frequent types of errors found in the translation output. Lotz and Rensburg also found that although the quality of the translations seemed to have improved up to 2012, this trend leveled off, with some of the 2013 output containing more errors than that of the previous year.

\section{Types of Texts}

There are different types of texts that can be submitted for translation. According to Reiss (1977/1989) texts are classified into three types: informative, expressive and operative. Informative texts are texts that transfer information, knowledge, opinions logically and referentially. The main focus of communication is the topic. Examples of this type of texts are news and scientific articles. Expressive texts refer to texts of high aesthetic value and when form is highly valued. Thus, translating expressive texts, such as literary works, requires optimal attention to the form, rhythm and other aesthetic values of the ST. One example of appellative or operative texts is advertisements, whereby the text producer appeals to the readers so as to do or not to do something (e.g. buying, selling ...etc.). Based on such a classification of texts, it may be presumed that informative texts are easier for MT than others, which are the focus of this article, in particular news texts. News texts are hypothesized to be easier than other types of texts in translation.

\section{METHODOLOGY}

\section{A. Research Design}

This study adopts a mixed method approach, as the researchers analyzed the source texts qualitatively. It is a descriptive analysis type of qualitative enquiry as the researchers, who are translators as well, examined the collected data, found the errors and provided corrections for the identified errors. Quantitatively, the errors were measured and assessed.

\section{B. Corpus of the Study}

The data was collected purposively from two main sources: Al Jazeera.net and Al Masryoon online newspaper as sources of informative texts... Al Jazeera was selected as one of the sources of the informative texts' data due to the high professionalism of the channel and the elevated type of Arabic language used in the phrasing of its headlines and news articles. As regards Al Masryoon, it was also selected because of the standard language used in most of its news articles. The data comprise some lines from news articles that were written in Standard Arabic and the raw output of the translation of the STs that were submitted to GT. GT was used because it is available for free and it is widely used (Drugan, 2013).

\section{Data Analysis}

The collected data was analyzed qualitatively using Hsu's (2014) model. In this regard, Hsu (2014) provided a more detailed typology of such errors as shown in Figure 1 below. This model classifies errors into orthographic errors, morphological errors, lexical errors, semantic errors and syntactic errors.

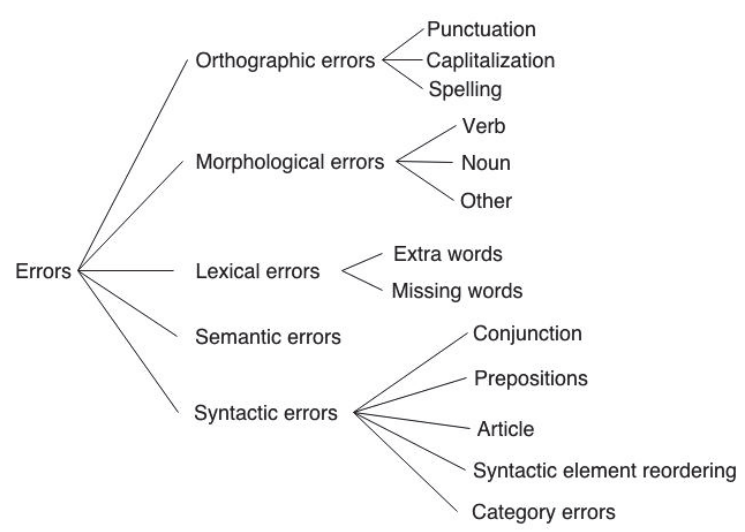

Figure 1: Classification of MT Errors (adopted from Hsu, 2014)

For the purpose of measuring the translation errors quality, errors were reclassified using the Multidimensional Quality Metrics (MQM) framework and Localization Quality Evaluation (LQE), whereby errors were classified into three types as follows: 
1. Minor errors: they are kind of errors that do not affect the comprehension of meaning while they affect fluency. The penalty error is assigned a score of 0.5 .

2. Major errors: they are kind of errors that make the TT difficult to understand, yet, the general message is conveyed. The penalty assigned to such type is 1 .

3. Critical errors: they refer errors that change the meaning of the ST and make it either incomprehensible or distorted. The penalty error assigned to such type is 3

As for measuring the adequacy and fluency of the MT output, human evaluators were used to answer a questionnaire (find it attached) that was adapted from Dorr, Snover, and Madnani (2011) Four monolingual native English evaluators were asked to rate the fluency of the translation output. Similarly four bilingual speakers were asked to rate the adequacy of the translation by comparing the translation output to the STs. In terms of fluency, raters were asked to judge the translation as follows:

$1=$ incomprehensible

2=disfluent English

$3=$ non-native English

$4=$ good

5=flawless English

As regards semantic adequacy, they were asked to assess the translation as follows:

$1=$ Meaningless (None)

$2=$ odd (Little meaning)

$3=$ partially meaningful (Much meaning)

$4=$ almost meaningful (most meaning)

$5=$ Meaningful (All meaning)

\section{RESULTS AND DISCUSSION}

This section of the article addresses the objectives of the research, which are identifying the common types of errors in the GT in the translation of informative texts from Arabic to English, measuring the translation errors quality and assessing the fluency and the semantic adequacy of the translation output, and therefore to explain the extent a human translator is needed to rectify the output translation

\section{Section 1. Types of errors}

\section{Syntactic errors}

As shown in Figure 1, syntactic errors can result from errors in articles, conjunctions, prepositions, syntactic order and word category. Examples of such errors are provided below.

Example 1

ST

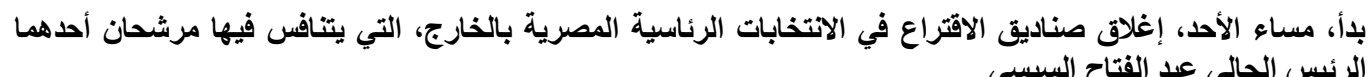

TT

On Sunday evening, the polls closed in the Egyptian presidential elections abroad, in which two candidates are competing, including current President Abdel Fattah al-Sisi.

As seen in example 1, GT provided an accurate translation of the ST. The meaning is generally understood. However, the syntax is contorted to some extent, giving rise to ambiguity. It seems that it is the polls that closed abroad, not the Egyptian elections. The meaning would be clearer to use the preposition "for" as in "...the polls for the Egyptian Presidential Elections". The overall meaning of the translation would also be clearer to separate the two sentences that speak of two different events happening in different parts of the world, though clearly inter-related. And perhaps the two different tenses serve to confuse the reader mixed in with the different events or subjects. The subject in the first phrase or sentence is "the polls" On Sunday..., the polls ... closed abroad and the subject happens to be overseas. The event happened in the past tense. The subject in the second phrase or the phrase, tacked on at the end, is the "two competing candidates" and the event is happening in the present progressive form of the verb or tense. This created confusion: Is the election happening in Egypt? Are the elections abroad or are the polls abroad? Or are they both the same thing? Clearly, or not so clearly, is it the overseas polling stations for Egyptian voters living abroad to vote for their elections back home that closed? Did both the overseas polls and the Egyptian Election close/stop at the same time? Are the candidates overseas competing?

Part of the problem is there are two prepositional phrase expressions "in the polls" and "in the elections" but the last plural referent is the Egyptian Presidential Elections, so maybe it is less problematic. But then 'abroad', a reduced locative prepositional phrase is tacked on at the end. It is like saying the two candidates are competing in the Egyptian Presidential Elections abroad where the polls have closed, as in the Egyptian Presidential Elections abroad. Or, they are competing in the polls abroad. In other words, because of the way the output is structured the meaning could be construed as the candidates are overseas competing in the Egyptian elections or in the polls when in fact, the two candidates are competing for a position in Egypt and the candidates are in Egypt. There are foreign offices assigned to register the votes of Egyptian citizens living abroad. If the output had been more clearly expressed in terms of syntax, 
there would not be any confusion or ambiguity. 1

Another error recorded is the dropping of the definite article "the" prior to the word "current". It was supposed to be translated as "the current ...."

Another example that shows a syntactic error can be seen in example 2 (in the section below). In example 2, the translation is ambiguous. Are the withdrawals related to the political scene or those specific candidates? The "political scene" is very vague. What about it? Or is it the withdrawals of those specific candidates that was related to the political scene? Separating the sentence of the output would make the meaning more clear: "Presidential election...or competitors .... Previous withdrawals from the presidential race, such as potential candidates like... and so and so, were related to the political scene, especially the swing to (right wing politics). Or just stop after the political scene, but without an explanation of what that was, it is not really saying much of anything. It remains vague or ambiguous or unclear. The meaning overall is hindered regarding clarity. Also, the repetition of the preposition "to" is creating some confusion. "The withdrawals from the race are related to ..." and "particularly to....."2

Semantic errors

Semantic errors result from the selection of a non-equivalent to the ST word, which might happen due to the linguistic ambiguity of the ST lexemes. Linguistic ambiguity might occur because of homophony or synonymy of the ST. Examples of semantic errors in GT outputs are provided below.

\section{Example 2 \\ ST}

TT

وتجرى الانتخابات الرئاسية دون وجود لمرشحين معارضين أو منافسين بارزين؛ جراء انسحابات سابقة من السباق الرئاسي منعلقة

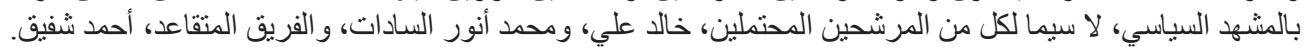
Presidential elections are held without the presence of prominent opposition candidates or competitors; previous withdrawals from the presidential race are related to the political scene, particularly to potential candidates Khaled Ali, Mohamed Anwar Sadat and retired team member Ahmed Shafiq.

A semantic error was found in the translation of the ST word الفريق which means "major general": resulting in "team" instead of "major general", which is a military rank. This error occurred because the ST word "الفريق"is a homonym of another Arabic word that means 'team'. Homonymy often causes linguistic ambiguity which results in semantic errors. Another semantic error occurred in the dropping of the ST word جراء (as a result of) in the TT, which affected the meaning. The ST expression implies that lack of candidates and competitors in the elections was due to the candidate's withdrawal from the elections.

Example 3

ST

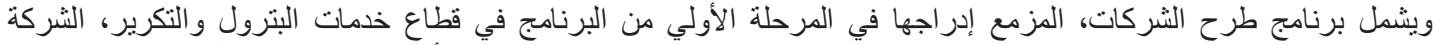

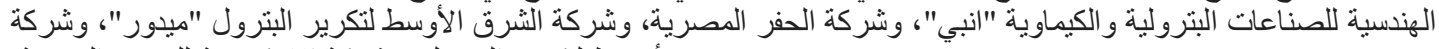

$$
\begin{aligned}
& \text { أسبوط لتكرير البترول، وشركة الإوسطرير الإسكندرية للزيوت النيخوت المعدنية. }
\end{aligned}
$$

TT The program of companies to be included in the first phase of the program in the oil and refining services sector includes the Engineering Company for Petroleum and Chemical Industries (ENPI), the Egyptian Drilling Company, Middle East Oil Refining Company (MIDOR), Assiut Oil Refining Company and Alexandria Mineral Oils Company.

The translation in example 3 is rather problematic. The first problem is the improper lexical choice of an equivalent of the ST word برنامج, which, in this context, does not mean "program"; it rather means "plan", or "the agenda of the following companies... is to ..." In the first instance of the word "program" which is an incorrect choice, the reader would have to construe it as the "roster" or the "list" "of companies to be included in ...". The translation problem applies to the second instance of the word "program" as well because this second use of "program" creates a problem. It is so vague: What program is being talked about? A program for creating Middle Eastern oil company alliances? Or what? That in itself then makes the text receiver wonder if "program" in the second case is also an incorrect word choice. A program for the renewal of this sector? Of development or redevelopment? A clean energy drive program due to environmental concerns? If "program" is the right word, then the translation should say what the program is ... state the name of the program. The second problem is omitting the word طرح meaning "selling" in the translation output, creating confusion in terms of meaning.

\section{Lexical errors}

Lexical errors, as explained in figure 1, occur due to the incorrect omission or addition of some lexemes or expressions above the word level, i.e., omitting necessary lexemes or adding unnecessary/incorrect lexemes or expressions. Examples of such errors in GT outputs are demonstrated below.

\section{Example 4}

ST

$$
\text { ووفق قرار الهيئة الوطنية للانتخابات بمصر (رسمية)، تنتهي مساء الأحد، عملية الاقتراع في اليوم الثالث والأخير لتصويت }
$$

\footnotetext{
${ }^{1}$ A better translation would be: "On Sunday evening, the polls for the Egyptian presidential elections closed here and abroad; two candidates are competing, including the current President AFAS."

${ }^{2}$ The meaning would be more clear if expressed like this: Previous withdrawals. from the presidential race, particularly such stellar candidates as Khalid Ali, Mohamad Anwar Sadat ..., are related to the political scene". if the meaning meant is that the withdrawals. are due to the political scene and/or not those specific candidates.
} 
TT According to the decision of the National Electoral Commission in Egypt (Sunday), the voting process ends on the third and final day of voting for the Egyptians abroad at 9:00 pm.

As seen in example 4, the output of GT left some parts of the ST untranslated. The final part of the ST that is "دقو كلت meaning "local time of each country" was left out in the translation output. Another issue, the word "Sunday" in brackets is vague. Is that when the decision was made? I.e., they met on Sunday and made a decision that day? Or, was it just reported on Sunday? Also, adding the missing item "living' to produce the phrase "Egyptians living abroad" sounds better.

It should be pointed out here that as a result of this omission, the meaning is contorted. It sounds like the translated version is saying that the voting process will end for the Egyptians who are abroad at 9 pm., but what about at the other times? Are there three days allotted for voting in Egypt and overseas? This lack of specification of who or what is where and when or what is happening where is creating confusion. Absolute specificity is needed in every part of the sentence. Referents cannot be ambiguous. Time zones... which time zones where? What is happening in what time zone? It is this lack of specificity, improper word use, referent confusion, etc. that is creating confusion or at least questions as to meaning.

Example 5

ST

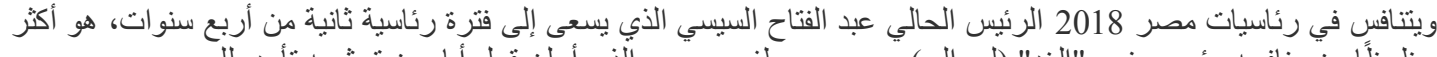

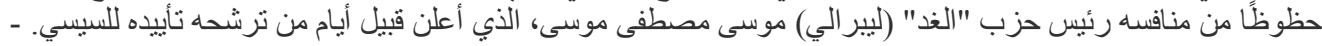

TT Egypt's president, Abdel Fattah al-Sisi, who is seeking a second four-year term, is more likely than his rival, the leader of the "Tomorrow" party, Musa Mustafa Musa, who announced days before his candidacy for Sisi. -

In example 5, the translation output is inaccurate on several counts. Some phrases were omitted in the TT output. For example, the first ST part that readsويتنافس في رئاسيات مصر 2018 الرئيس الحالي was deleted in the TT, which created some confusion and misunderstanding. Similarly, the ST phrase أكثر حظوظنات "has more chances of winning" was rendered as "more likely", leaving some parts of the ST meaning untranslated. The ST phrase means "more likely to win" or "more likely to succeed than his rival" or "has a greater chance of winning". Also, the ST word wheans "his support", was not translated in the TT. This might be a result of the ST complexity, as it is not clear whether "announced ...his candidacy" refers to Al Sisi, to "his candidacy for president, "his candidacy for the presidential race, or ... "his candidacy for the leader of the opposition party. The text receiver assumes that the rival is the "who" that announced he is in the running for presidency. It would be a more natural translation to place the head noun "Musa Mustafa Musa" in clause-initial position followed by the modifying noun phrase "leader of the "Tomorrow" party, and the modifying relative clause "who announced his candidacy for the presidency just days before".

\section{Example 6}

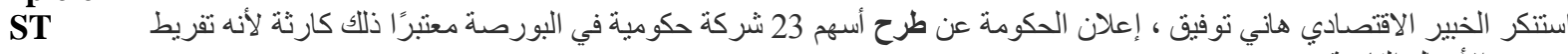
في حق الأجيال القادمة

TT

The economic expert Hani Tawfiq denounced the government's announcement of the shares of 23 government companies on the bourse as a disaster because it is a violation of the rights of future generations.

In example 6, there is the problem of deleting some words/information in translation that exist in the ST. For instance, the ST word طرح was not translated in the translation output. So the part that reads as "announcement of the shares of" in the TT should be corrected by adding the word "selling" before the phrase "of the shares". Similarly, the ST expression معتبرًا ذللك "considering it" was not translated in the TT.

Such a lexical error creates confusion and raises questions like: What is the disaster here? The announcement? It is more the action to do with the shares that is the disaster. Also, what is the referent of deictic "it"; couldn't "it" also refer to bourse? Can you denounce an announcement? It is usually said that so and so declared the government's hoarding of their shares or selling off of their shares to foreigners as a disaster. Or perhaps so and so denounced the government's practice of or policy of or whatever action they took.

Example 7

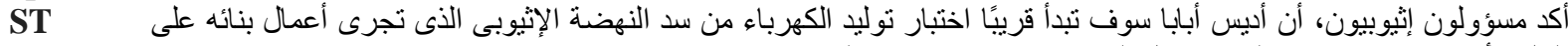

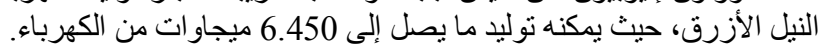

TT Ethiopian officials have confirmed that Addis Ababa will soon begin testing electricity generation from the Nahdha dam, which is being built on the Blue Nile, where it can generate up to 6,450 megawatts of electricity.

In example 7, there seems to be no problem with the translation. This shows that sometimes GT produces accurate translation if the lexical items in the ST are not ambiguous or the structure of the ST is quite complex. The ST adjective word الإثيوبى was omitted in the TT; however, this did not affect the meaning because the word is implicitly understood in the TT.

There is one issue to note. Since "it" can anaphorically have two referents, the dam and the river, accuracy is lost or maybe the meaning is confusing. Is it the dam or the river that generates the electricity? It is probably both. Where there can be more than one referent, name the referent again in order to obtain clarity of meaning, and achieve lexical 
cohesion through repetition. The word "dam" should be capitalized as it is part of a proper noun.

\section{Example 8}

أكد وزير الخارجية الإثثيوبي، ورقبنو قبيو، اليوم الأحد، تمسك بلاده بإعلان المبادئ الذي سبق ووقعته قبل نحو 3 سنوات، مع كل من ST 8 من

TT Ethiopian Foreign Minister Vardino Kabio confirmed on Sunday his country's adherence to the Declaration of Principles signed three years ago with Egypt and Sudan on the dam.

In example 8, the translation seems to be accurate but one problem arose in the translation of سد النهضة as "the dam" instead of "the Renaissance Dam". This again highlights the problem of omission of some parts of the ST in the TT. This case also illustrates structural ambiguity in the sense that the translation is open to two interpretations due to using the preposition "on" heading the prepositional phrase "on the dam" instead of "in reference to the dam". This has resulted in structural ambiguity which confused the meaning: Was the declaration signed on the dam? Or is the signing of the Declaration with reference to the dam?

\section{Example 9}

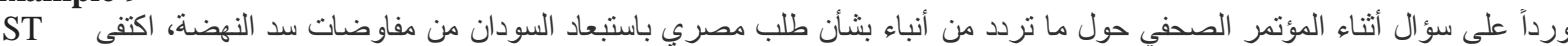

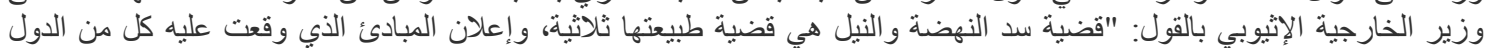
الثلاث ينص على ذللك صر احة"

TT In response to a question during the press conference about the reports of an Egyptian request to exclude the Sudan from the Nahdha Dam negotiations, the Ethiopian Foreign Minister said: "The issue of the dam of Nahdha and Nile is a trilateral issue. The Declaration of Principles signed by each of the three states explicitly states that "He said.

The translation of example 9 sounds good with the exception of the inaccurate use of "He said" at the end of the quotation marks. The quote is already preceded by "the Ethiopian Foreign Minister said", thus the unnecessary repetition/redundancy of the subject and verb at the end resulted in incorrect usage and confusion as if there were another person expressing comments. Only the Ethiopian Foreign Minister is talking.

\section{Example 10}

ST ال الكاتب الصحفي مصطفي بكري عضو مجلس النواب، إن الفريق أحمد شفيق تعجل في إعلان ترشحه للرئاسة، حيث كان مقرر إعلان ذلك من فرنسا يوم 22 ديسمبر القادي مئب

TT Journalist Mostafa Bakri, a member of the House of Representatives, said that the team Ahmed Shafiq is rushing to announce his candidacy for the presidency, where he was scheduled to announce it from France on 22 December.

Again in example 10, the problem is translating الفريق as "the team", which is incorrect as explained earlier. There is also semantic ambiguity of anaphoric reference where "his" could refer back to Bakri or to Shafiq, and anaphoric reference problem of "he" in "he was scheduled to announce. This confusion could be prevented by the translation ... Shafiq's candidacy rather than his. Where? Exactly what where? The House of Reps? Again, lack of specificity is creating a lack of clarity and confusion.

A lexical problem is attested in the wrong choice of the wh-word "where". The last translated phrase is awkward. "Where" refers to place, but the issue and main topic of discussion is the timing or the date of the announcement. That would be paired with "which". It is a "which", not a "where". 3 Is France/the place of particular importance? Not really. It would be usual to translate the text like "which was scheduled to take place on Dec 22 in France. Or which was scheduled to take place in France on Dec. 22". The "where" has a different referent than the "which". When the text recipient reads "where", the recipient is predisposed to have certain expectations, to think in a certain way and to be set up in a certain mind frame. The reader is confused. What is this translation trying to say? What is this about? I personally wonder am I to assume now that the where is taking over from the which? ...that the where is the focus now? When in fact the phrase was just tacked on at the end to give more information but it was of little consequence.

\section{Example 11}

ST من جهتها، أعربت مفوضية اللاجئين التابعة للأمم المتحدة عن قلقها من تفاقم جديد للأزمة الإنسانية في سوريا بعد النزوح الكبير بسبب

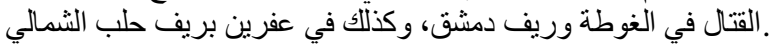

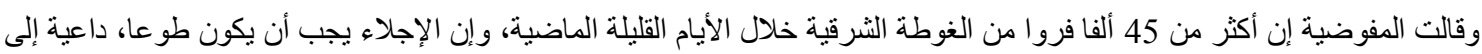

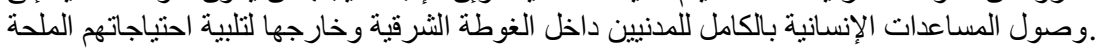

TT The United Nations High Commissioner for Refugees (UNHCR) has expressed concern about a new worsening of the humanitarian crisis in Syria following the massive displacement caused by the fighting in Ghouta and the countryside of Damascus, as well as in Afrin, the northern suburb of Aleppo.

UNHCR said more than 45,000 people had fled the eastern Ghouta over the past few days, and the evacuation must be voluntary, calling for full humanitarian access for civilians inside and outside the eastern Ghouta to meet their urgent needs.

As seen in example 10, the translation seems to be free of error, which is more than likely due to the rich available resources of both the ST and TT. The translation should have said the Ghouta region in this last paragraph. It would

\footnotetext{
${ }^{3}$ An adequate and acceptable translation could be "...which was scheduled to be announced by Shafiq". Or perhaps "which candidacy was to be announced". Or just "Shafiq's candidacy for presidency ... which Shafiq was scheduled to announce".
} 
seem that that is missing. There should have been an apostrophe after The United Nations because it is possessive. We assume it is the Commissioner who is speaking on behalf of this organization.

If the noun displacement is used, it must be followed by specifying of what, i.e., "... of 45000 residents of Arfin and its suburbs". Or ".... of Syrian citizens from the Ghouta valley". Or "of ... its citizens". That is to say the noun displacement requires a prepositional phrase complement as part of its lexical meaning. Also, to prevent further confusion, there should be no mixing of different events together, especially if they occur at different times and in different places and involve different players. In the present case, so and so is concerned about the worsening humanitarian crisis in Syria caused by fighting in Ghouta region, or in Aleppo and the subsequent displacement of 45,000 refugees. So and so proposes to evacuate the refugees to a safer area, but insists/stresses that the evacuation must be voluntary.

The adjective "new" is not needed. It is getting worse, so that is a new event/phenomenon/situation. The determiner "the" before fighting can be left out. This part about the evacuation must be voluntary is poorly understood. Aren't the people fleeing? That is their idea or their will. They are in control then... evacuations are usually done by some organization or governments, one would assume.

Also the tenses are being mixed up here. So, the people fled and there is to be an evacuation. This problem has cropped up before (see the example above) with the mixing of tenses and events and/or players or places, which causes confusion. It is better to make two separate sentences, or divide the sentences by a semi-colon.

\section{Example 12}

ST

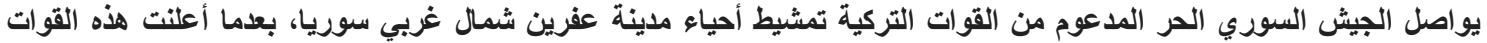

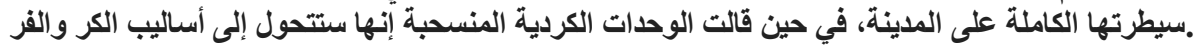

TT The Free Syrian Army, backed by Turkish troops, continues to comb the neighborhoods of Afrin city, northwest of Syria, after they announced full control over the city. The retreating Kurdish units said they would turn to hit-and-run tactics.

The problems in this translation are grammatical, semantic and lexical. The plural pronoun "they" has two possible referents - the Turkish troops or the "neighborhoods of Afrin. If the pronoun "they" could be used for the army as well, then in that case, there would be three possible anaphoric references. ${ }^{4}$ The second sentence is correct and clear. However, it would be more clear to say the Kurdish troops would resort to..... Or they would resume hit-and-run tactics... if they had used them before but stopped them for some reason. The reason we are saying this is because habitual language usage can lead to language expectations. You anticipate hearing something but you get something different and it throws the recipient off (i.e., turn left or right or turn to hit someone or something or can turn to (meaning into) dust etc...

The overall meaning is pretty well understood - that the Free Syrian Army has gained full control of the city and made the announcement. However, since the plural referents in relation to "they" could be taken in an ambiguous manner, it poses some issues in terms of complete clarity and grammatical perfection.

\section{Morphological errors}

Morphological errors occur at the level of verbs, nouns and other aspects of morphology. An example of such error can be found in example 10, as the ST verb تعجل, which is a past tense, was translated into "is rushing", which is a present progressive aspect." In example 1, the ST lexical items بدأ إغلاق were rendered as 'closed', which is a morphological error since the ST noun إغلاق was rendered as a verb and the ST verb بدأ was omitted. The omission of the ST verb بدأ in the TT reflects a lexical error.

Based on the analysis provided, this research shows that there are some frequent errors in GT's translation output, such as omission and inappropriate lexical choice. Thus, a human translator is needed to rectify the output translation. However, this research also illustrates that GT is a useful system that helps expedite the translation process.

Section 2. Measuring the Translation Errors quality

Figure 2 below shows the severity of the translation errors found in the GT output, which is based on the raters' feedback.

\footnotetext{
${ }^{4}$ This issue could easily be solved by omitting "they" and replacing it by "after announcing".... or even better....After regaining full control over Afrin city, northwest of Syria, (Or in the northwest of Syria. Either it is in Syria or not) and announcing their victory, the Free Syrian Army, backed by Turkish troops, continue to comb the city's neighborhoods.
} 


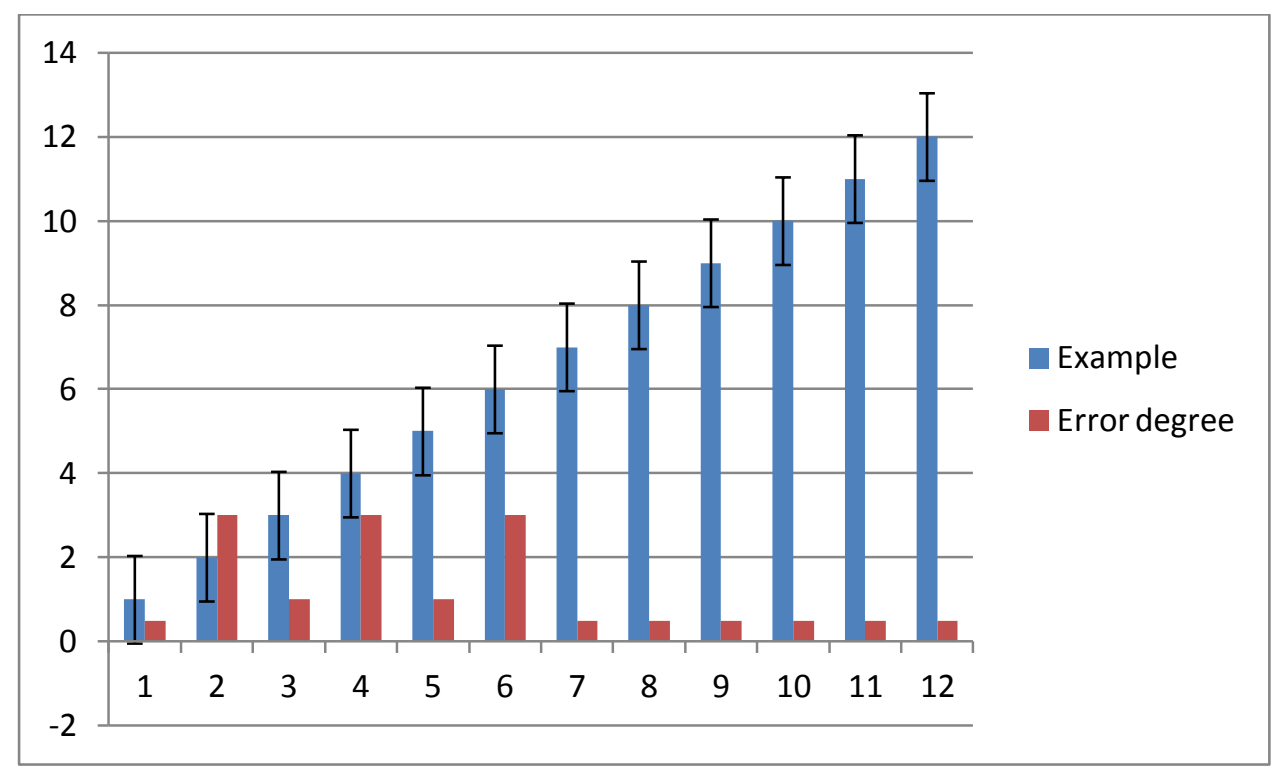

Figure 2: Quality of Translation Errors

As seen in figure 2, some errors were found to be serious (examples 2, 4 and 6), as they change the meaning or make the translation output incomprehensible. However, some errors were found to be major (examples 3 and 5), as the message is understood with difficulty. Some other errors (examples 1, 7, 8, 9, 10, 11, 12) were found to be minor, as they do not affect the meaning intended in the ST. Overall, most errors were found to be minor.

Section 3: The fluency of the MT output

Two assessors rated the fluency as showing some fluency (with some errors) while one assessor rated it as good. The average rating score of the first assessor was found to be 3.69 while the third assessor's average rating score was found to be 3.84. As for the second assessor, the average rating score was found to be 4.15 . Since the average score was above 3 , it can be inferred that the translation is considered as relatively 'good' Figure 3 below shows the fluency rating provided by the three assessors.

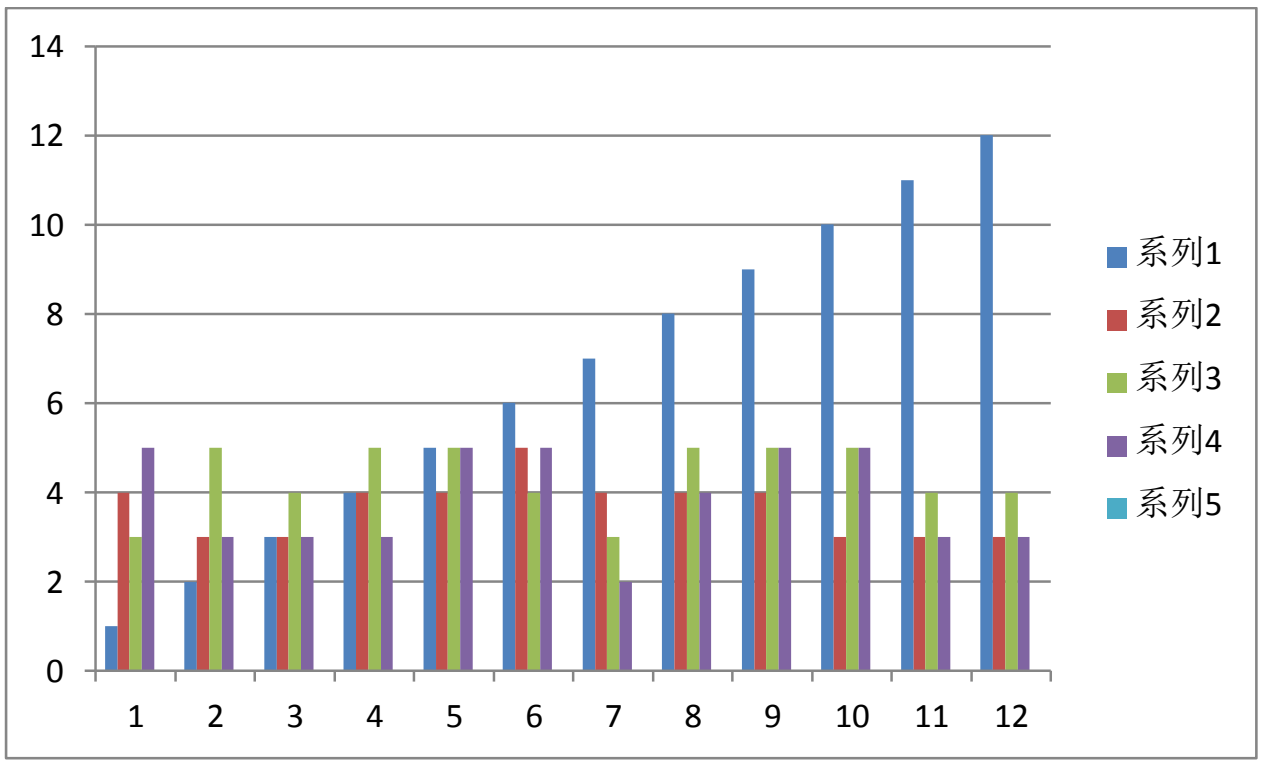

Figure 3: Fluency Rating

\section{Section 4: The adequacy of the MT output}

The evaluators assessed the translation as highly adequate. In other words, the translations were found to be highly semantically adequate. The figure below shows the assessment of semantic adequacy. 


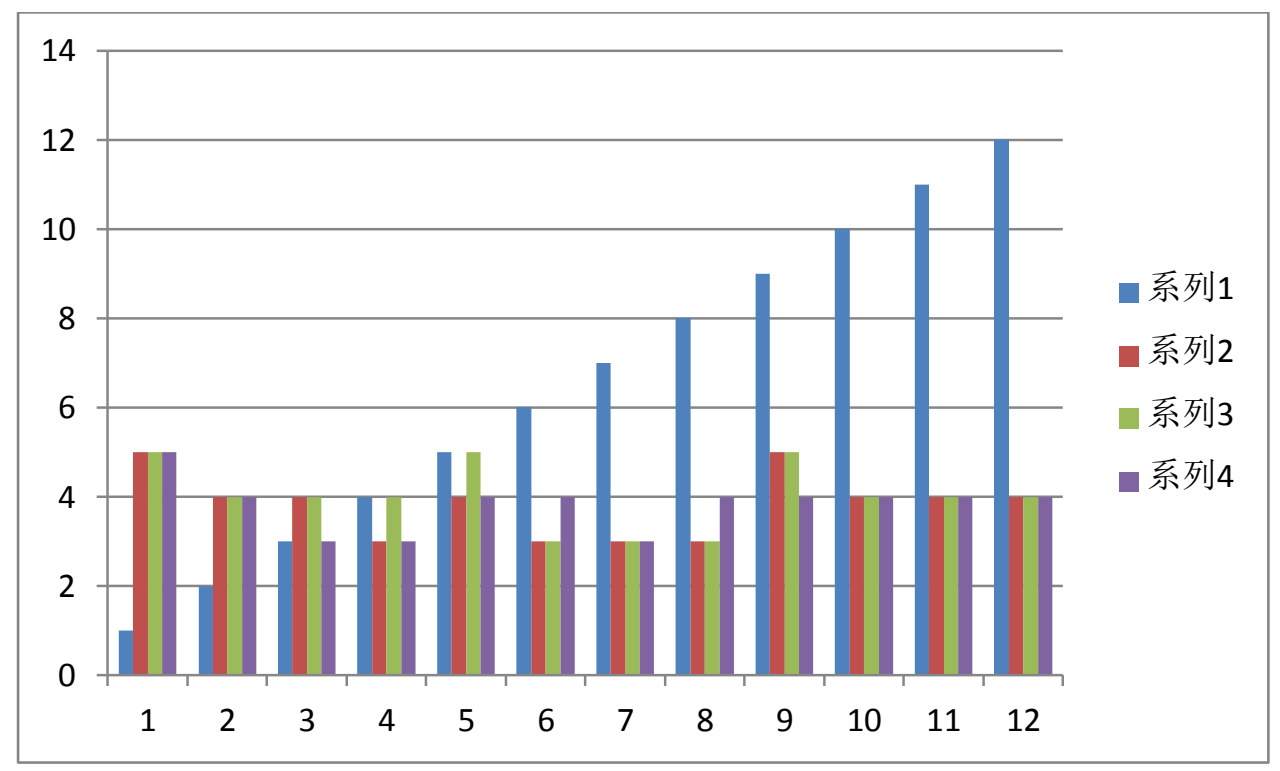

Figure 4: Semantic Adequacy of MT Output

As seen in figure 4, the three assessors rated the semantic adequacy as almost totally meaningful. The average rating score provided by the first assessor and the third assessor was found to be 3.92 while the score provided by the second assessor was found to be 4.7. This shows that GT was found to be of great support for translators.

\section{CONCLUSION}

The article aimed at examining the common errors in the raw output of GT. It also aimed at examining the quality of the translation errors, the semantic adequacy and the fluency of the translation output... For this purpose, texts from different sources were selected. Different types of errors were found in the output translation. As regards, the quality of the translation errors, most of them were found to be minor errors. For, fluency, it was found that the translation show some fluency (with some errors). Also, semantic adequacy was found to be high. This research concludes that GT is a very important and effective system that can help expedite the translation process. Future studies that provide solutions to reduce the errors found in the MT output are recommended.

\section{REFERENCES}

[1] Abdel Monem, A., Shaalan, K., Rafea, A. \& Baraka, H. (2009). Generating Arabic text in multilingual speech-to-speech machine translation framework. Journal of Machine Translation, 22(4), 205-258.

[2] Abu-Ayyash, E. A. (2017). Errors and non-errors in English-Arabic machine translation of gender-bound constructs in technical texts. Procedia Computer Science, 117, 73-80.

[3] Aiken, M., \& Balan, S. (2001). An analysis of Google Translate accuracy. Translation Journal, 16 (12). Retrieved at 5 pm on 10/12/2019 from http://www.translationdirectory.com/articles/article2320.php.

[4] Arnold, D.J., L. Balkan, R.L. Humphreys, S. Meijer and L. Sadler (1994). Machine Translation: An Introductory Guide Cambridge. Ma. /Oxford: Blackwell.

[5] Aziz, W., Sousa, S., \& Specia, L. (2012). PET: A Tool for Post-editing and Assessing Machine Translation. International Conference on Language Resources and Evaluation, 3982-3987. Turkey. Retrieved at 6 pm on 12/12/2019 from http://www.mt- archive.info/Aslib-2012-Aziz.

[6] Balkan, L. (1998). Machine-aided Translation. In Baker, M. (Ed.), Routledge Encyclopedia of Translation Studies, 134-148. New York: Routledge.

[7] Castilho, Gaspari, Moorkens and Way. Integrating machine translation into moocs. Proceedings of EDULEARN17 Conference, 3rd-5th July 2017, Barcelona, Spain.

[8] Condon, S., Parvaz, D., Aberdeen, J., Doran, C., Freeman, A., \& Awad, M. (2010). Evaluation of machine translation errors in English and Iraqi Arabic. Mitre Corp Mclean Va.

[9] Dagneaux, E., Denness, S., \& Granger, S. (1998). Computer-aided Analysis. System, 26, 163-174. Elsevier. Retrieved at 6 pm on 11/12/2019 from http://www.sciencedirect.com/science/article/pii/S0346251X98000013.

[10] DeCamp, J. (2009). What is Missing in User-Centric MT?. Proceedings of the MT Summit. Ottawa, Canada.

[11] Dorr, B., Snover, M., \& Madnani. (2011). Chapter 5: Machine Translation Evaluation. In Dorr, B., Olive, J., McCary, J., \& Christianson, C. (2011). Machine translation evaluation and optimization. In Handbook of natural language processing and machine translation (pp. 745-843). Springer, New York, NY.

[12] Drugan, J. (2013). Quality in Professional Translation. Assessment and Improvement. London: Bloomsbury.

[13] Gaspari, F., A. Toral and S. Naskar. (2011). User-focused task-oriented MT evaluation for wikis: A case study. Proceedings of the Third Joint EM+/CNGL Workshop "Bringing MT to the User: Research Meets Translators".

[14] Handschuh, C. (2013). Human Translation vs. Machine Translation: A Triumph of Nuance over Nonsense?. Retrieved at 3 pm on 5/12/2019 from http://dculs.dcu.ie/dcu-languageservices-news/human-translation-vs-machine-translation. 
[15] Hearne, M. and A. Way. (2011). Statistical Machine Translation: A Guide for Linguists and Translators. Language and Linguistics Compass 5(5): 205-226. doi: 10.1111/j.1749-818x.2011.00274.x.

[16] Hutchins, J. (2007). Machine translation: A concise history. Computer aided translation: Theory and practice, 13(29-70), 11.

[17] Jia, Y., Muyun, Y., Junmao, M., Dongqing, X., Tiejun, Zhao., \& Sheng, L. (2012). How Good is Web Based MT: A Case Study on Paper Title Translation. International Conference on Asian Language Processing, 40, 213-216. Retrieved at $7 \mathrm{pm}$ on 6/12/2019 fromhttp://www.computer.org/.

[18] Juan, Du. (1994). Machine Translation for a Group Decision Support System. Master of Science. Department of Information Systems and Computer Science. National University of Singapore

[19] Karami, O. (2014). The Brief View on Google Translate Machine. Retrieved at 8 pm on 01/12/2019 from http://ceurws.org/Vol-867/Paper17.pdf.

[20] Keshavarz, M.H. (1999). Contrastive Analysis and Error Analysis. Tehran: Rahnama Press. Retrieved at 9 pm on 01/12/2019 from http://bookyar.net/?paperno=142803.

[21] Komeili, Z., Jalil, F.H., \& Ali, R. (2011). An Investigation of the Translation Problems Incurred by English-to-Persian Machine Translation:"Padideh, Pars, and Google Softwares".Procedie-Social and Behavioral Sciences, 28, 1079-1082.

[22] Koponen, M. and L. Salmi. (2015). On the correctness of machine translation: A machine translation post-editing task. Journal of Specialised Translation 23: 118-136.

[23] Lotz, S., and Rensburg, A. Van. (2014). Translation technology explored: Has a three-year maturation period done Google Translate any good ? Stellenbosch Papers in Linguistics Plus, 43(1), 235-259. http://doi.org/10.5842/43-0-205.

[24] Ping, K. (2009). Machine Translation. In Baker, M. \& Saldanha, G. (Ed.). Encyclopedia of Translation Studies. (2nd ed.). New York: Routledge.

[25] Popović, M. and Ney, H. (2007). Word Error Rates: Decomposition over POS Classes and Applications for Error Analysis. In Proceedings of the Second Workshop on Statistical Machine Translation, pp. 48-55.

[26] Valotkaite, J. and M. Asadullah. (2012). Error detection for post-editing rule-based machine translation. Proceedings of the Association for Machine Translation in the Americas, Workshop on Post-editing Technology and Practice.

[27] Vilar, D., Xu, J., D’Haro, L., and Ney, H. (2006). Error Analysis of Statistical Machine Translation Output. Proceedings of the LREC. 697-702.

Noureldin Mohamed Abdelaal holds a PhD in translation and interpretation, preceded by an MA in English applied linguistics. $\mathrm{He}$ is an assistant professor of translation at the University of Nizwa. His research interests and publications are in the areas of translation and applied linguistics.

Abdulkhaliq Alazzawie is an associate professor at the University of Nizwa. He has worked for different universities in different parts of the world including Canada and United Arab Emirates. His research interests and publications are in the areas of syntax, translation and applied linguistics. 